\title{
QUANDO A “DÉCIMA MUSA" INSPIRA RAPS E TAMBORES: DOS USOS POLÍTICOS DA FIGURA DE SAFO POR VOZES LÉSBICAS E FEMINISTAS NO BRASIL CONTEMPORÂNEO*
}

\author{
Lettícia Batista Rodrigues Leite ${ }^{1}$
}

\begin{abstract}
Resumo
O objetivo deste artigo é chamar atenção para uma dimensão da recepção das memórias em torno da poeta Safo e da Ilha de Lesbos: aquela representada pelos usos políticos feitos por militantes e grupos feministas e, sobretudo, lésbico-feministas. Será por meio da apresentação e comentário de dois exemplos encontrados atualmente, no Brasil, que pretendo chamar atenção para a pertinência da análise dessa modalidade de recepção.
\end{abstract}

\section{Palavras-chave}

Safo de Lesbos; feminismo; lesbianidade; política.

\footnotetext{
* Uma primeira versão deste texto foi elaborada e apresentada oralmente no Ciclo de Palestras da equipe de Arqueologia da Unicamp, Laboratório de Arqueologia Pública Paulo Duarte, no Instituto de Filosofia e Ciências Humanas da Unicamp, no dia 18 de abril de 2016. Palestra feita a convite do professor Dr. Pedro Paulo A. Funari. Agradeço a ele e à professora Dra. Maria Aparecida A. Almeida pela organização do evento.

1 Doutora pela Universidade de Paris I - Sorbonne, Paris, França. E-mail: leitele@yahoo.com.br
} 


\begin{abstract}
The object of this article is to draw attention to a dimension of the reception of the memories around the poet Sappho and the Island of Lesbos: that represented by the political uses made by militants and feminists groups and, above all, lesbian-feminist groups. Through the presentation and commentary of two examples currently found in Brazil, that I intend to draw attention to the relevance of the analysis of this type of reception.
\end{abstract}

Keywords

Sappho of Lesbos; feminism; lesbianity; political. 


\section{Safo de Lesbos: memórias em fragmentos}

Quero começar este artigo evocando um vazio: o espaço da folha em branco com o qual a escritora feminista francesa Monique Wittig e a cineasta estadunidense Sande Zeig preenchem o verbete "Sappho", que compõe o léxico intitulado Brouillon pour un dictionnaire des amantes (Wittig; Zeig, 2001 [1976]: 188.). Vazio que eu vou tomar aqui como uma provocação com a qual eu procurarei dialogar, apontando para algumas sugestões interpretativas passíveis de justificar essa relação entre "Safo" e o vazio/o silêncio, materializada por Wittig e Zeig em seu verbete sem definição. Tomo esse mote do vazio, também como recurso introdutório capaz de me conduzir a uma aproximação com o objeto de estudo que ora me interessa, e que é explicitado pelo subtítulo escolhido para este texto: "(d)os usos políticos da figura de Safo por vozes lésbicas e feministas no Brasil contemporâneo". Usos esses dos quais tratarei na segunda parte do artigo, a partir de dois exemplos.

Uma primeira constatação que sem dúvida faz jus à associação entre a poeta de Lesbos e o "vazio" remete à escassez de informações relativas à Safo e à ilha de Lesbos, onde ela viveu entre os séculos VII e VI a.C. Nesse sentido, vale lembrar logo de início que, afora outras esparsas referências², as duas mais extensas notas biográficas relativas à autora, às quais têm-se hoje acesso, encontram-se em um papiro datado entre os séculos II/III d.C., e em uma entrada de um léxico bizantino: a $S u d a$, do IX/X d.C. Trata-se, pois, de conteúdos produzidos cerca de sete e dezesseis séculos após o período durante o qual Safo vivera, os quais reproduzo abaixo:

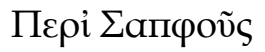

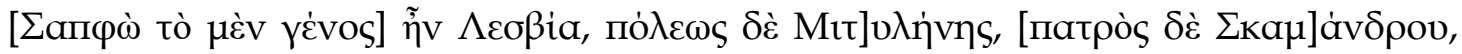

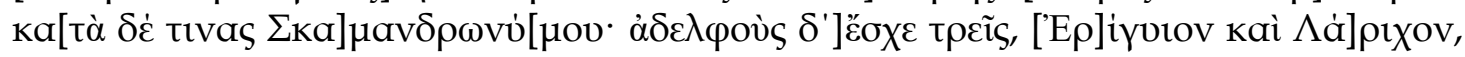

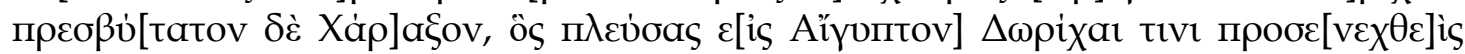

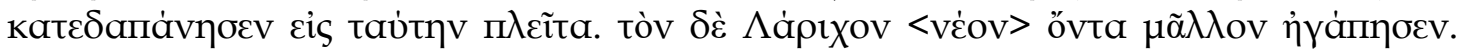

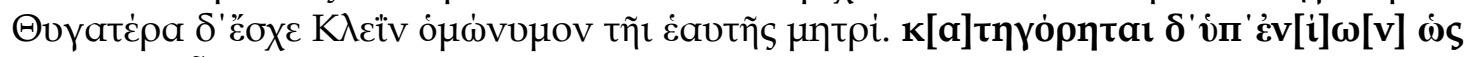

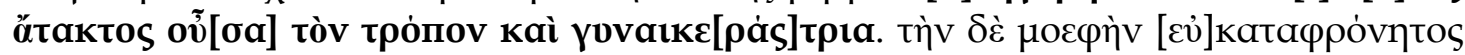

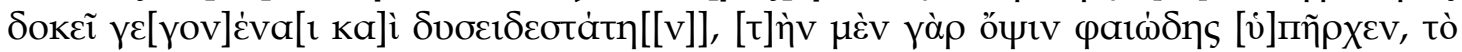

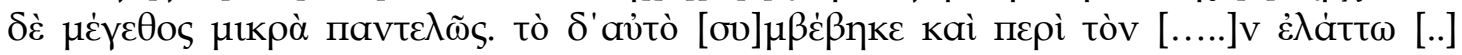
үعүov< $<\mathrm{o} \tau>\mathrm{a}[$ ...... (P. Oxy. 1800, fr. 1, col. I, 1. 16-19 e 1.19-24).

[Sobre Sa]ppho

[Sappho, pelo nascimento,] era le[sbiana, da cidade de Mit]ylene; [seu pai foi Scam]amándro, ou, se[gundo outros, Ska]mandro[nymos]; ela teve três [irmãos], [Er]ýgios e Lá]rikhos, o mais velho, Kháraxos, que partiu para o Egito ligando-se a uma certa de Dórikha, gastando largas somas com ela. Preferia o <jovem> Lárikhos.

\footnotetext{
2 David A. Campbell reúne 61 delas, que versam sobre os mais variados aspectos, sob o nome de "Testimonia Vitae atque Artis". Campbell (1994).
} 
Teve uma filha, Kleís, que levava o nome de sua mãe. Foi acusada, por alguns, de ser irregular em seus caminhos e amante de mulheres. Parece que tinha um físico ordinário e muito feio, de tez escura e de estatura muito pequena. O mesmo é verdade em relação a [ ] que era [ (Tradução: Fontes, 2003: 121-122. Grifos meus)

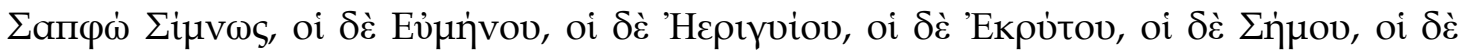

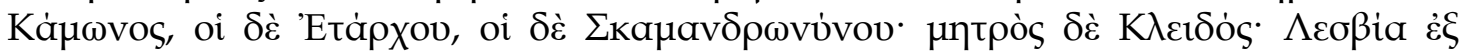
'E

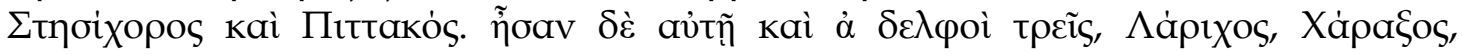

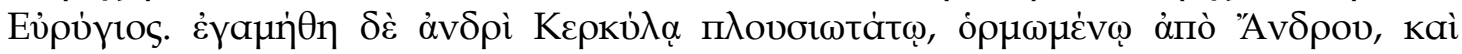

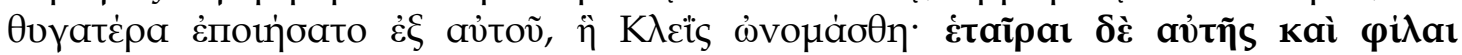

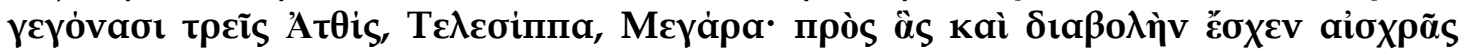

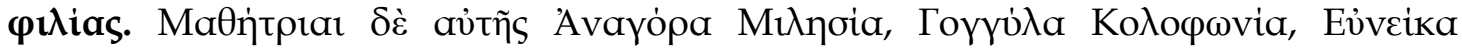

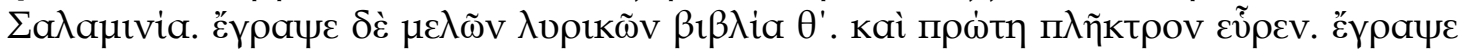

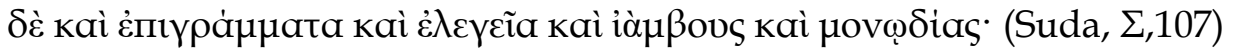

Sappho, filha de Símeon, ou, segundo outros, de Eyménos, ou de Eerígyos, ou de Ekrítos, ou de Sémos, ou de Kâmon, ou de Etárkhos ou de Skamandronýmos; sua mãe foi Kleís. Nasceu em Mitylene de Lesbos; poeta lírica, floresceu na $42^{\mathrm{a}}$ Olimpíada, época em que viveram também Alkaîos, Stesíkhoros e Pitakkós. Teve três irmãos: Lárikhos, Kháraxos e Eyrýgios. Desposou Kérkylas, homem muito rico, vindo de Ándros, e teve com ele uma filha, de nome Kleís. Teve três companheiras ou amigas: Átthis, Telessíppa, Megára, e adquiriu má nome por sua amizade impura com elas. Suas discípulas foram Anagóra de Mileto, Gonghýla de Kolóphon, Eyneíka de Salamina. Escreveu nove livros de poesia lírica, e inventou o plectro. Escreveu, também, epigramas, elegias, iambos e monodias. (Tradução: Fontes, 2003: 122. Grifos meus)

Ambos os textos trazem, entre outras informações, a data e/ou local em que Safo teria nascido, atribuem nomes à sua mãe, pai, irmãos, filha, marido, assim como fazem alusões às suas relações com mulheres. Dados que, além de sua questionável veracidade, não nos trazem maiores informações sobre o contexto de produção das composições sáficas. Seja como for, diante do fato de que, desde a Antiguidade, Safo tenha sido considerada uma refinada compositora, podemos presumir da sua privilegiada condição social. Posição que, em grande parte, poderia explicar o seu acesso a uma educação, por intermédio da qual ela viria a tornar-se uma celebrada compositora. Reconhecimento ao qual, ademais, pode-se creditar parte da circulação que suas composições tiveram no decorrer dos séculos, e que nos permitiu o conhecimento, muito embora extremamente limitado, que ainda hoje temos de algumas de suas composições.

Isso nos leva, pois, ao segundo aspecto que reforça a associação de Safo à imagem de uma página em branco: a condição de fragmentos na qual as composições a ela atribuídas chegaram até o presente. Atualmente, as edições mais respeitadas trazem cerca de duzentas delas. Nesse sentido, e apenas para se ter uma ideia do tamanho das perdas envolvidas, vale lembrar que, aquela 
que seria a primeira edição antiga dos poemas de Safo - preparada pelos Alexandrinos, e que remonta ao século III a.C. -, teria sido composta por nove volumes. Dentre os quais, conjectura-se, apenas o primeiro comportaria de sessenta a setenta cantos - ou seja, cerca de $30 / 35 \%$ do que conhecemos hoje (Côrrea apud Ragusa, 2005: 15).

Além disso, cabe ressaltar o fato de que, dentre os fragmentos que costumam compor as edições modernas, o conteúdo de apenas um é tido como completo. Trata-se da chamada "Ode a Afrodite". Composição cuja sobrevivência se deve, sobretudo, à sua transmissão indireta por intermédio de um tratado do século I a.C.: Sobre o arranjo das palavras, de Dionísio de Halicarnasso (Ragusa, 2005: 262). Tratado no qual Dionísio cita a composição sáfica para atestar a sua apreciação que não poupa elogios à eufonia e à graça da qual o seu ouvinte poderia desfrutar. Atributos que, segundo o autor, seriam efeitos da disposição das palavras ao longo da mesma. Tal comentário é igualmente interessante, por sublinhar de forma flagrante o caráter oral que permanecia associado à produção e recepção das composições sáficas ainda no século I a. C.

De resto, a citação de Dionísio é um excelente exemplo do reconhecimento que, desde a Antiguidade, as composições atribuídas à Safo gozavam. Isso, a ponto de podermos encontrar referências nas quais Safo é não apenas comparada a ninguém mais ninguém menos do que Homero ${ }^{3}$, como também listada e/ou comparada às Musas, a ponto de ser até mesmo caracterizada em um desses testemunhos como a "Décima Musa" 4 .

Nesse sentido, não causa surpresa que, em um tratado posterior em cerca de um século àquele de Dionísio: o Do Sublime - tratado cuja datação e autoria, embora sujeitas a controvérsias, é normalmente credita a (Pseudo)Longino -, o seu autor cite uma outra composição sáfica como nada mais nada menos que o modelo do sublime. Apreciação graças à qual se deu a transmissão de um dos fragmentos mais discutidos do corpus sáfico, o "Fr. 31". Fragmento que foi não apenas objeto de uma centena de traduções e variações poéticas ao longo dos séculos (Brunet, 1998), mas também, embora muito mais tarde, pretexto para debates intensos acerca da "natureza" do éros - e de seus perturbadores efeitos - cantados pelos poemas de Safo (Devereux, 1970).

Isso posto, quero por fim apontar para a terceira e última modalidade de silêncio, ou talvez seria melhor dizer, de silenciamento ou tentativa de, capaz

\footnotetext{
${ }^{3}$ Anth. Pal 7.15 (Campbell, 1994: 46-47); 9.26 (Waltz, 1957 : 11-12).

4 Para Safo comparada/colocada entre as Musas cf.: Anth. Pal 7.14 (test. 27), 7.17(test. 28), Ovídio, Tristes 2.363-5 (test. 49) 7.407 (test. 58), 9.26, 9. 571.9f. (Campbell, 1994: 26-28; 28-31; $42-43 ; 48-49)$.
} 
de justificar a associação materializada por Wittig e por Zeig, no supracitado léxico, entre Safo e a ausência, isto é: a questão da mise en scène poética, em alguns dos fragmentos sáficos, de um desejo que, no presente, poderia ser qualificado como "homoerótico", ou mesmo "lésbico". Silêncio/silenciamento que, em parte, remonta aos antigos e que, entre outros, constitui um dos aspectos apontados pela pesquisadora Sandra Boehringer em seu livro L'homosexualité féminine dans l'Antiquité grecque et romaine (2007), no qual a autora nos oferece um minucioso estudo dos discursos antigos sobre as relações amorosas e/ou sexuais entre mulheres.

De fato, levando-se em conta o material ao qual hoje temos acesso, é apenas no final do século I a.C. que encontramos não apenas a primeira alusão, mas também menções diretas, que apontam para uma assimilação desse homoerotismo enunciado em alguns dos fragmentos atribuídos a Safo, à própria compositora. Refiro-me, respectivamente, a um excerto da ode de número XIII, do segundo livro de Horácio ${ }^{5}$, e a dois trechos da hoje célebre XV carta que compõe as chamadas Heroidas de Ovídio ${ }^{6}$, nos quais Safo é posta em cena pelo poeta rememorando seus antigos amores por jovens mulheres ${ }^{7}$. Quanto à associação da Ilha de Lesbos, ou das "mulheres lésbicas" à prática homoerótica, por sua vez, sem que no entanto Safo seja sequer mencionada, vamos encontrá-la de forma inequívoca ${ }^{8}$ apenas no século I d.C., no V,1 Diálogos das cortesãs (I d.C.) de Luciano - que constitui nada mais nada menos que uma das passagens mais longas da literatura antiga abordando a temática das relações sexuais entre mulheres (Boehringer, 2007: 349-356).

Sandra Boehringer (Boehringer, 2007: 313) sublinha ainda que, até pelo menos por volta do século II d.C., quando o "homoerotismo feminino" era invocado, não era o nome da poeta de Lesbos o mais comumente associado a essa prática, mas sim o de Filenes - autora/personagem sobre a qual pouco sabemos, mas cujo nome encontra-se ligado à autoria de um manual erótico antigo (Boehringer, 2007: 275-314). De modo que, se é por volta do século I d.C. que encontramos as primeiras ocorrências ${ }^{9}$, em latim, de tribas - um dos termos que é usado nos discursos antigos para designar essa modalidade

\footnotetext{
${ }^{5}$ Horácio, Odes, II, 13, 24-25.

${ }^{6}$ Demarchi (2012: 1), alerta para o fato que: “As epístulas atribuídas a Ovídio foram reúnidas pela primeira vez sob o título de Heróides pelo gramático Prisciano de Cesareia no século V. Foi somente em 1629 que Daniel Heinsius numerou as cartas e a Carta de Safo ficou conhecida como a Carta XV."

7 Ovídio, Heroides, XV, 15-20; 201-204. Para a análise da carta de "Safo à Faon", cf. Boehringer (2007: 215-223).

${ }^{8}$ Ver, no entanto, as polêmicas discussões em torno do fragmento 358 (Fr. 358 Poetae Melici Graeci) atribuído a Anacreonte (VI a.C.), em Boehringer (2007: 60-66).

${ }^{9}$ Fedro, Fábulas, IV, 16: Sëneca, Controvérsias, I, 2, 23. Passagens analisadas por Boehringer (2007: 261-271).
} 
erótica ${ }^{10}$ que, ao que tudo indica, é percebida como pouco ortodoxa -, é o nome dessa última, "Filenes", que aparece com maior frequência associado ao mesmo. Isso ao ponto que, em um dos epigramas de Marcial (I d.C.) Filenes encontra-se caracterizada como "a tríbade dentre as tríbades" (ipsarum tribadum tribas $)^{11}$. O nome de Safo, por sua vez, só aparecerá associado a esse mesmo termo uma única vez, no século III d.C, em um comentário feito a uma ode de Horácio'12, em que a poeta é referida como "mascula Safo". Qualificação que o comentador justificará por intermédio de duas hipóteses: "mascula, seja pelo seu talento na arte poética, geralmente atributo de homens, seja pela sua reputação como tribas."13

Contudo, apesar desse quase completo silêncio dos textos e imagens antigas que nos chegaram - e eu diria, em parte, graças a ele -, associando Safo e a ilha de Lesbos ao homoerotismo explicitamente expresso no gênero feminino; e, apesar do fato de Safo não representar para/não ser representada pelos antigos como a figura tipo em matéria de homoerotismo, Safo e a ilha de Lesbos figuram, ainda hoje, em pleno século XXI, como duas incontornáveis referências "lésbicas". Uma breve busca no Google por "Ilha de Lesbos" /"Safo de Lesbos", serve de amostra para o alcance do processo de produção discursiva em torno da poeta e de sua ilha natal.

Um dos efeitos mais populares de tal associação aparece na duplicação do sentido semântico do adjetivo "lésbica", que é derivado do topônimo "Lesbos". Tal adjetivo, que outrora se restringia a designar uma mulher nascida na ilha, passaria nos idos do século XIX a qualificar também mulheres que mantinham relações eróticas com outras mulheres. Do que vai derivar, ainda, e em diversas línguas, o substantivo "lesbianismo" - empregado para fazer referência, de forma mais precisa, ao "homossexualismo"/homossexualidade quando praticada por mulheres, e que é atualmente declinado, no Brasil, sobretudo nos contextos de lutas sociais, nas formas "lesbianidade", "lesbiandade".

10 Para uma lista das ocorrências de tribas, de tрıßà e frictrix/ficatrix, ver Boehringer (2007: 272).

11 Marcial, Epigramas, VII, 70. Filenis aparece caracterizada como tríbade também no epigrama VII, 67. Ambos os epigramas são analisados por Boehringer (2007: 288-294). Note que Filenes aparece em outros sete epigramas do autor: II, 33; IV, 65; IX, 29, 40, 62; X, 22 et XII, 22 igualmente analisados pela autora, p. 294-298. Filenes aparece como personagem

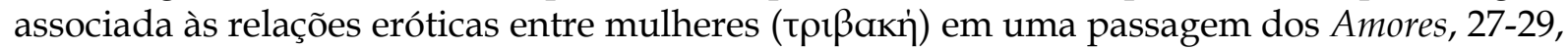
atribuído a Pseudo-Luciano (II-IV d.C.). Para um comentário desse texto ver ainda uma vez Boehringer (2007: 295-306).

12 Horácio, Épode, I, 19, 28.

${ }^{13}$ Commentun in Horati Epistulas, I, 19, 28, 3. A tradução é minha. 
Como busquei sugerir no título, proponho-me aqui, justamente, a comentar dois exemplos contemporâneos que atestam a vivacidade da referida associação entre Safo, a Ilha de Lesbos e o lesboerotismo, vinculadas a pautas políticas precisas. Tratarei, em um primeiro momento, da menção ao nome da poeta e da sua ilha natal encontrada na letra de uma rapper feminista independente, negra, lésbica e paulistana, chamada Luana Hansen. Minha segunda escolha recairá sobre a opção pelo nome da poeta para designar um grupo cearense de percusionistas negras, lésbicas e bissexuais, chamado "Tambores de Safo".

\section{Safo e a Ilha de Lesbos: inspirações contemporâneas}

A escolha dos dois "casos" apontados acima justifica-se, a meu ver, uma vez que ambos exemplificam, de forma bastante contundente, a potência política da qual fragmentos de mémórias podem ser investidos, por intermédio de usos cujos objetivos são bastante claros, e para as quais os fins justificam os meios, sem disfarces. Mas não só. Chamou-me atenção o fato de que essas atuações, essas vozes, têm em comum - entre si, e com a poética sáfica - o fato de se inscreverem em um universo musical cujo cadência vocal e/ou rítmica são produzidas por mulheres. Enunciações que, no entanto, hoje, - distantes do contexto em que as composições sáficas teriam sido realizadas ${ }^{14}$ - são potencializadas politicamente dentro e por uma perspectiva de lutas sociais de caráter lésbico-feministas-antirracista.

No caso do rap "Les Queens", composto por Luana Hansen em parceria com Dory de Oliveira e Tiely Queen, é possível notar, de forma clara, a sua inscrição em um esforço político que propõe a intercesão de várias pautas: feministas, antirracistas, de classe, assim como de lutas encampadas pelos movimentos LGBT's, a partir do final da década de 1980, e reforçadas, sobretudo, no decorrer da década de 1990. Ações em larga medida atreladas a um esforço de positivação e visibilidade das identidades gays e, em menor escala, lésbicas, bissexuais e trans (Facchini, 2003).

\footnotetext{
14 Para um exemplo de análise comparativa entre os cantos sáficos e produções musicais contemporâneas, ver Calame, 2015: 69-92.
} 
É preciso, contudo, assinalar o fato de que vou me ater, aqui, a um breve comentário de parte da letra15: aquela que compõe o seu terceiro momento, a qual reproduzo abaixo:

O meu Machado de Labrys, vai ficar na memória

Fazendo você entender um pouco da nossa história

da ilha de Lesbos, a poetisa Safo,

sou Salzikrum a filha Macho

criadas pra lutar contra a lesbofobia

hoje são muitas guerreiras nesta correria

intolerante a qualquer tipo de racismo

se for pra brigar ai deixa que eu brigo

linha de frente atravessando todas as cidades

fazendo a lésbica ter visibilidade

uma mulher que ama outra mulher

e merece respeito por que sabe o que quer

a minha mente engatilhada causa terrorismo

estou pra acabar de vez com o machismo

atrevida e que arrasta multidão

pode me chamar se quiser a sapatão

o nosso grito se espalha em forma de arte

onde existir o preconceito entramos pro debate

de todos os lugares sente a nossa malandragem

o exército é a favor da liberdade. (Grifos meus)

Nessas duas estrofes, escritas e cantadas por Luana Hansen, aparece, com nitidez, a ênfase à questão da visibilidade lésbica ou sapatão, vinculada ao combate contra a lesbofobia, o racismo e o machismo. Logo de início, a rapper lança mão da estratégia de reforçar uma memória, buscando dar a ouvir um pouco de uma história qualificada pelo adjetivo possessivo declinado no feminino plural "nossa". Será assim, por intermédio da evocação de referências/símbolos historicamente, e por razões diversas, vinculados e resignificados como "emblemas lésbicos" - o "machado de Labrys"16, a Ilha de

15 A letra da música me foi gentilmente enviada pela própria Luana Hansen. O rap, na íntegra, encontra-se disponível em: https:// soundcloud.com/les-queens/les-queens. Acesso: 19 nov. 2017.

16 Termo proveninete do grego $\lambda \dot{\beta} \beta \rho u s$, que significa machado. Na página da Labrys, Revista de Estudos Feministas, encontramos o seguinte explicação: "Labrys em grego significa "dupla acha", dupla lâmina, machado duplo. Arma ou instrumento, era utilizada pelos povos das Amazonas. Das profundezas da história humana, em torno de 7000/6500 a.C, nos planaltos da Anatólia - Turquia de hoje -, em Çatal Huyuk, (talvez a primeira aglomeração humana registrada), a imagem da dupla lâmina estava associada aos cultos do feminino, às imagens da Deusa, criadora de todas as coisas". Disponível em: https://www.labrys.net.br/labrys26/labrysbr.html. Acesso: 19 nov. 2017. 
Lesbos e a poetisa Safo, assim como a figura da "Salzikrum"17 -, que essa voz busca ao mesmo tempo legitimar as suas lutas e exortar as mulheres a atuarem como verdadeiras guerreiras contemporâneas na luta em prol de maior liberdade e respeito.

Limito-me a chamar atenção para a evocação à "ilha de Lesbos" e à "poetisa Safo", que aparece no terceiro verso da primeira estrofe supracitada. Ressalto, aqui, um uso que faz uma opção política de reatualizar não apenas uma dentre as inúmeras memórias associadas à poeta de Lesbos - aquela de uma Safo amante de mulheres -, mas que o faz, por intermédio de uma performance vocal, rítmica e corporal enunciada no gênero feminino. Forma de enunciação que, conscientemente ou não, em alguma medida, faz eco ao que se conjectura ser a forma de comunicação das composições sáficas na Antiguidade.

O grupo "Tambores de Safo", por sua vez, atua desde o ano de 2010, tendo suas atividades inicialmente vinculadas ao grupo militante LAMCE Liberdade do Amor entre mulheres no Ceará (2004) ${ }^{18}$. Grupo que, nas palavras de suas integrantes, trata-se de:

[...] um grupo musical, que pretende através da música e da arte, contribuir para [o] pensamento crítico feminista e o empoderamento das mulheres, visando o combate ao machismo, ao racismo e à homofobia e as mais diversas opressões capitalistas ${ }^{19}$.

A simples escolha do seu nome, que evoca a poeta de Lesbos, poderia ser suficiente para a opção de incluí-lo nesse artigo, tendo em vista que ela faz de Safo uma figura precursora-legitimadora de um grupo de percussão que preconiza o amor entre mulheres. Mas, as próprias atividades propostas pelo grupo, que incluem: rodas de debate, oficinas de produção dos instrumentos de percussão e performances musicais, a meu ver, o tornam parte ativa de uma espécie de dupla reatualização de memórias atribuídas à Safo. Memórias que incluem, entre outras coisas: a criação de um instrumento (o "plectro"20), a direção de uma espécie de grupo/escola para jovens mulheres, práticas lésbicas (eventualmente com algumas dentre as jovens do grupo) e a

\footnotetext{
17 Termo proveniente do Código de Hamurabi, que parece referir-se às sacerdotisas e pode ser traduzido como "filhas/muheres-varão/macho". O termo é usado para referir-se àquelas que poderiam ter uma ou várias esposas e que teriam direitos à herança e à propriedade semelhantes aos dos homens.

18 O grupo LAMCE foi inicialmente intitulado LANCE, sigla para "Lésbicas Atuantes no Ceará". No entanto, a mudança de nome reflete o fato de que muitas das mulheres partícipes não se consideravam lésbicas, uma vez que mantinham também relações heteroafetivas e heterossexuais (Oliveira, 2015).

19 Disponível em: https://pt-br.facebook.com/pg/batucadatamboresdesafo/about/. Acesso: 19 nov. 2017.

${ }^{20}$ Cf. supra: Suda, $\Sigma, 107$.
} 
composição de alguns cantos nos quais se expressa um desejo homoerótico. Isso posto, vale em seguida destacar as justificativas apresentadas pelas próprias componentes para explicar a escolha do nome de Safo.

Em uma breve apresentação do grupo e de suas atividades, que pode ser encontrada no site da organização "Articulação de mulheres brasileiras", é possível ler:

O nome "Tambores de Safo", escolhido por todas as participantes do grupo, é uma referência à poetisa e intelectual grega Safo, conhecida por fazer política através da arte. Em sua história está a fundação de uma escola de artes para moças que foi cenário de muitas cenas apaixonadas entre ela e suas discípulas. Devido Safo ter vivido toda sua vida em cidades da Iha de Lesbos, hoje mulheres que se relacionam afetivo-sexualmente com outras mulheres são conhecidas como lésbicas. ${ }^{21}$

Nesse mesmo sentido, apresento, ainda, a transcrição de trecho de uma fala de uma das integrantes do "Tambores" que, em um documentário sobre o grupo, aparece explicando tal escolha em termos semelhantes aos apresentados na citação acima:

O nome "Tambores de Safo", ele surge é no coletivo. Nós queríamos colocar algo que identificasse que existiam os tambores, que existem os batuques, né, que existe essa coisa afro, brasileira, nordestina. Mas também queríamos um outro nome que representasse essa questão da lesbianidade. Então a gente começou a refletir sobre Safo, né. Safo é uma poetisa grega, né, da Grécia, poetisa e filósofa, que ensinava o amor entre as mulheres, na Ilha da Lesbos, e daí surge o próprio nome "lésbicas" também. Então a gente resolveu fazer essa homenagem à Safo, e ficou "Tambores de Safo". Mas pensamos em vários nomes né, pensamos em "Sapatuque", em é "Tambores lésbicos", "Batuque feminista", "Tambores feministas", mas algo que identificasse fortemente. E o que nos identifica fortemente são os tambores e as discussões que permeiam sobre Safo. $(0: 32-1: 49)^{22}$

Argumentos que me permitem afirmar que, foi um processo de compartilhamento de memórias em fragmentos sobre Safo e sua ilha, entre as integrantes do grupo, que lhes possibilitou chegar à escolha do nome da poeta como o mais adequado para acompanhar o substantivo "tambores". A poeta de Lesbos aparece, então, como uma referência que parece ser entendida como sendo capaz de condensar os atributos que correspondem, de forma mais precisa, ao projeto de atuação político-artística vislumbrada pelo grupo, desde a sua crição, e sobretudo no que tange a uma questão precisa: a lesbianidade.

${ }^{21}$ Texto disponível em: http://articulacaodemulheres.org.br/tambores-de-safo/. Acesso: 19 nov. 2017.

22 Documentário disponível em: https://www.youtube.com/watch?v=uLmVEG_yByU. Acesso: 19 nov. 2017. 
A partir dos dois exemplos apresentados acima, é sem dúvida com um uso político deliberado da figura histórica de Safo e da Ilha de Lesbos com a qual nos deparamos aqui. Procurei, pois, apresentar, ainda que de forma breve, um território ao meu ver ainda pouco explorado por parte daqueles e daquelas que se dedicaram ao estudo das recepções dos fragmentos de Safo e das ressignificações em torno das esparsas memórias sobre a poeta e sua ilha.

Com efeito, diferentemente dos círculos literários e debates acadêmicos intermináveis, nos quais durante anos e ainda hoje circula uma espécie de "grande debate" que opõe aqueles e aquelas que, grosso modo, defendem ou se incomodam/se ofendem com a possibilidade de se pensar em uma Safo de Lesbos como uma "lésbica" em termos contemporâneos; algumas vozes feministas, sobretudo lésbico-feministas, costumam se apropriar e afirmar, sem pudores, a potência contida na leitura de uma Safo de Lesbos lésbica. Proponho, assim, concluir este artigo com algumas poucas considerações acerca desse debate.

\section{Safo lésbica política}

Foi muito provavelmente na esperança de ajudar a pôr fim à verdadeira querela acerca da "orientação sexual" da poeta de Lesbos que, em em seu artigo de 1989, intitulado "Safo lésbica e Safo de Lesbos", André Lardinois foi categórico ao afirmar:

Na verdade, essa é uma questão sem sentido, mesmo se, pelos padrões modernos, Safo devesse ser considerada lésbica, sua experiência deve ter sido muito diferente, vivendo, tal como viveu, em uma era diferente com diferentes noções e tipos de sexualidade (Lardinois, 1995: 50).

Levando-se em conta o material do qual dispomos hoje, de fato me parece no mínimo imprudente para qualquer pesquisadora ou pesquisador afirmar ou infirmar se Safo, a compositora, teve experiências afetivas e/ou eróticas com as jovens meninas em um quadro pedagógico, ou mesmo com outras mulheres. $\mathrm{O}$ que temos, eu reitero, são cantos atribuídos à poeta, dentre os quais alguns põem em cena uma voz "homoerótica" - assim como algumas das composições atribuídas a Alcman (séc. VII a.C.) -, sinalizando para a existência social desse homoerotismo que, no caso de Safo, é textualmente explicitado no feminino sem conotação negativa alguma (Calame, 1996).

Ademais, é sempre imprescindível ressaltar que, na Antiguidade grega e romana, não encontramos equivalente algum para as nossas noções de "sexualidade", e tampouco para aquelas de "homossexualidade" e 
"heterossexualidade" (Boehringer; Brisson, 2003: 199). Sendo assim, Safo não pode ser de fato "lésbica", uma vez que a existência de uma "orientação sexual" nem mesmo fazia sentido no contexto em que ela viveu.

No entanto, acredito ser pertinente pontuar ainda uma vez que, essa questão se enche de sentido, sobretudo nos idos do século XIX, em grande parte embora certamente não apenas -, à emergência da noção de "sexualidade", assim como daquelas que seriam consideradas suas modalidades desviantes. Assim sendo, nesse contexto emerge também uma fobia latente nos discursos de alguns filólogos preocupados, entre outras coisas, em defender a poeta de Lesbos da fama de ser uma "homossexual", uma "tríbade". Oposição que busca operar, em grande medida, como contra-discurso frente ao florescimento que se assiste, desde pelo menos o século XVII, nos círculos literatos ingleses e franceses, de referências literárias diversas nas quais a temática "sáfica" despontava, e por vezes Safo ela mesma era acusada ou louvada pelo seu "safismo" 23 .

Seja como for, fato incontestável é que Safo se constituiu e permaneceu, no decorrer dos séculos, como um modelo de inspiração (poética) inequívoco, para muitas autoras ou autores, seja pela qualidade de suas composições, pelo fato de que seus fragmentos representam uma das raras vozes enunciadas no feminino ou, ainda, pelo seu teor homoerótico (Marks, 1979: 356). Disso são certamente ecos os usos positivados que muitas feministas e lésbicas fazem de Safo, no decorrer do séculos XX e XXI, não hesitando em se apropriar politicamente dos vazios históricos em torno da figura da poeta e de sua ilha, de modo a legitimar as suas posições políticas e identidades.

É nesse sentido, como veremos na própria obra de Monique Wittig - e para muito além do silêncio que ela e Zeig materializam na página em branco do verbete aludido no início deste texto -, que atuam também as vozes lésbicas e feministas que são hoje produzidas no Brasil, e para as quais a leitura de Safo como incontestavelmente lésbica é investida de um caráter explicitamente político. Releitura essa que, como procurei defender aqui, também merece nossa atenção.

\footnotetext{
${ }^{23}$ A forma nominal "safismo" surge no final do século XIX com a conotação inequívoca de "homoerotismo no feminino", seja no universo literário europeu, seja em tratados médicos dedicados ao estudo e classificação das "perversões" sexuais caracterizadas como especificamente femininas (Chaperon, 2008).
} 


\section{Referências Bibliográficas}

BOEHRINGER, Sandra. L'Homosexualité féminine dans l'Antiquité grecque et romaine. Paris: Les Belles Lettres, 2007.

BOEHRINGER, Sandra; BRISSON, Luc. Grèce Antique. In: TIN, LouisGeorges (dir.). Dictionnaire de l'homophobie. Paris: PUF, 2003.

BRUNET, Philippe. L'égal de dieux. Cent versions d'un poème de Sappho. Paris: Allia, 1998.

CALAME, Claude. L'éros dans la Grèce Antique. Paris: Belin, 1996.

CALAME, Claude. Chanter les vulnérabilités: des poèmes de Sappho au rap bernois, du modèle choral au paradigme néolibéral. Cahiers du genre, $\mathrm{n}^{\circ}$ 58/1, 2015, p. 69-92.

CAMPBELL, David (ed.). Greek lyric I - Sappho and Alceus. $3^{\text {rd }}$ ed. Cambridge: Harvard University Press, 1994. (The Loeb Classical Library).

CHAPERON, Sylvie. La médecine du sexe et les femmes. Anthologie des perversions féminines au XIX siècle. Paris: La Musardine, 2008.

DEMARCHI, Cristiane. Entre imagens e Safo: apontamentos de uma pesquisa. Anais do XXI Encontro Estadual de História, ANPUH-SP. Campinas, 2012. Disponível em: http://www.encontro2012.sp.anpuh.org/resources/anais/17/1342396006_A RQUIVO_EntreimagenseSafotexto2.pdf. Acesso: 19 nov. 2017.

DEVEREUX, George. The nature of Sappho's seizure in Fr. 31 LP as evidence of her inversion. The Classical Quarterly, vol. 20, no. 1, 170, 1970, p. 17-31. Disponível em: http://www.jstor.org. Acesso: 03 abr. 2016.

FACCHINI, "Regina, Movimento homossexual no Brasil: recompondo um histórico". Cad. AEL, vol. 10, n. 18/19, 2003, p. 81-125.

FONTES, Joaquim Brasil. Éros, tecelão de mitos: a poesia de Safo de Lesbos. 2 ed. São Paulo: Iluminuras, 2003.

LARDINOIS, André. Safo lésbica e Safo de Lesbos. In: BREMMER, Jan (org.). De Safo a Sade: momentos na história da sexualidade. Campinas: Papirus, 1995, p. 27-50. 
MARKS, Elaine. Lesbian Intertextuality. In: MARKS, Elaine; STAMBOLIAN, George (éd.). Homosexualities and French Literature. Ithaca and London: Cornell University Press, 1979, p. 353-377.

OLIVEIRA, Cláudia Feritas de. O Movimento lésbico em Fortaleza - LAMCE: trajetória e ações de luta. Cadernos de História. Belo Horizonte, v. 16, n. 24, 2015, p. 83-102.

RAGUSA, Giuliana. Fragmentos de uma deusa: a representação de Afrodite na lírica de Safo. Campinas: Editora de Unicamp, 2005.

WALTZ, Pierre. (ed.). Anthologie Grecque. Première Partie - Anthologie Palatine. Tome VII (livre IX, épigr. 1-358). Paris: Les Belles Lettres, 1957.

WITTIG, Monique; ZEIG, Sande. Brouillon pour un dictionnaire des amantes. Paris: Grasset, 2001 [1976]. 